\title{
Production of Silica from Agricultural Waste
}

\section{N Sapawe* and MF Hanafi}

Universiti Kuala Lumpur, Malaysian Institute of Chemical and Bioengineering Technology, Lot 1988 Vendor City, TabohNaning, Melaka, Malaysia

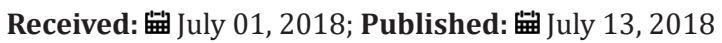

*Corresponding author: Norzahir Sapawe, Universiti Kuala Lumpur, Malaysian Institute of Chemical and Bioengineering Technology, Lot 1988 Vendor City, TabohNaning, 78000 Alor Gajah, Melaka, Malaysia, Tel: 6013-5757-795; Email: norzahir@unikl.edu.my

\section{Abstract}

This study aims to produce silica from different material agriculture waste such as sugarcane bagasse, bamboo culm, bamboo leaf, and corncob. The sol-gel method was applied in order to produce silica using $1 \mathrm{M} \mathrm{NaOH}$ and $1 \mathrm{M} \mathrm{H}_{2} \mathrm{SO}_{4}$. The sugarcane bagasse ash contains the highest amount of silica, $92.5 \%$ followed with bamboo leaf, $62.72 \%$; corncob, $27 \%$; and bamboo culm, $20 \%$.

Keywords: Silica; Agriculture Waste; Sol-Gel

\section{Introduction}

The most common generated waste synthesized is rice husk and palm ash, which shown high silica contain as $90-98 \%$ and 45 $50 \%$, in respectively [1,2]. Silica produced from these wastes were synthesized mainly using acid leaching treatment. In this study, we focused on the synthesized of other sources silica through sol-gel method. The source such as sugarcane bagasse, corn cob, bamboo stem, and bamboo leaf, till now is still not widely explored, hence become the basis to study the amount of silica that been extracted. Within the scope of study, it shown that several factors play a vital role in determining the silica content of the material, including the species of source material, soil content of source material, maturation etc. Sol-gel synthesis is one of the most common method of converting ash into silica gel. In this process, silica was synthesized from ash through simultaneous hydrolysis and condensation reaction where a sol of sodium silicate, silicon alkoxide or halide gels converted into a polymeric network of gel [3]. The synthesis of silica using this method, lead to silica precipitation under certain conditions like restriction of gel growth that involved coagulation and precipitation step during its preparation [4]. Silica gel synthesize through this method also known as xerogel. The purification and drying produce silica in amorphous powder form that remove any impurities or organic matter that usually contain in waste [1]. Therefore, in this study, herewith, we explore the production of silica from these material waste using sol-gel method.

\section{Experimental}

Sugarcane bagasse (SBA), corn cob, bamboo culm(Gigantochloascortechinii), and bamboo leaf were collected from various sources in Melaka, Malaysia. Reagents used are $\mathrm{NaOH}$ (HmBg chemical) and sulphuric acid (HmBg chemical). The collected materials were sorted, cleansed and cut to smaller portion. The prepared material was transferred into furnace and combusted at $6500^{\circ} \mathrm{C}$ for 3 hours at a heating rate of $10^{\circ} \mathrm{C} \mathrm{min}^{-1}$ to obtain ash. The ash was then collected and labelled accordingly based on the sources material.The silica was prepared by boiling $30 \mathrm{~g}$ of ash with $1 \mathrm{~L} 1 \mathrm{M} \mathrm{NaOH}$ for 1 hour with constant stirring until ash dissolved and sodium silicate solution produced. The solution filtered, and the residue washed with distilled water. The filtrate then cooled to room temperature and later adjusted to $\mathrm{pH}$ 7 using $1 \mathrm{M} \mathrm{H}_{2} \mathrm{SO}_{4}$ and $\mathrm{IM} \mathrm{HCl}$ using titration method. The gel was performed and was let to age for 18 hours. The formed gel then gently broken and centrifuged at $2500 \mathrm{rpm}$ for 10 minutes. The supernatant was discarded, and the gel dried for 11 hours at $80^{\circ} \mathrm{C}$ to form xerogel. It then washed with deionized water to remove minerals and impurities.

\section{Results and Discussion}

The aim of this study is to analyse the synthesis of silica from different type of selected silica material. From experimental procedure, $4.7 \mathrm{~kg}$ sugarcane bagasse produce 1.3\% ash after combustion and this ash contain $92.5 \%$ silica. These results are in concordance with previous study that suggested that SBA contain higher silica content from 50\%-97\% range [5,6]. This higher silica synthesis is due to the higher fibre contain of sugarcane bagasse that made up of lignin (20-30\%), cellulose (40-50\%) and hemicellulose (30-35\%) [7]. Nonetheless, ash produced from the 
combustion of sugarcane bagasse is quite low, only at $1.3 \%$ from total weight used. Based on this result, it shown that sugarcane bagasse ash contains the highest amount of silica, $92.5 \%$ and it is almost similar with the amount of silica synthesized from rice husk which stated between 90-98\% [1]. This suggesting that sugarcane bagasse is a good source of silica and has wide potential for further study and application. Figure 1 shown the silica \% content of the all materials have been studied.

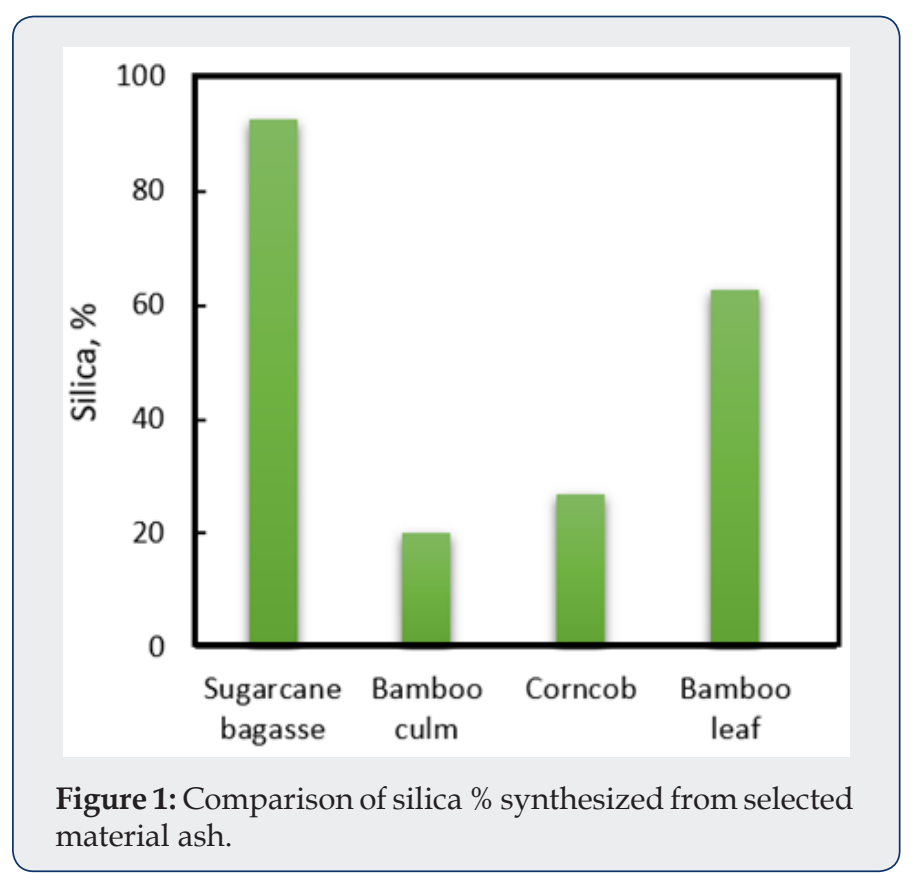

\section{Conclusion}

In this study, it is confirmed that we successfully extracted silica from different selected materials ashes that usually generated as waste from agricultural. Sugarcane bagasse produce the lowest percentage of ash from all the selected wastes material, 1.3\%; however, contain the amount of highest silica, $92.5 \%$ which is almost similar with the amount of silica produced from rice husk. Another generated that can synthesise higher silica \% is bamboo leaf, $62.7 \%$. Others generated waste such as bamboo culm and corncob ash can synthesise about $20 \%$ and $27 \%$ respectively.

\section{Acknowledgement}

The authors are grateful for the financial support by the University Kuala Lumpur (UniKL MICET) and Majlis Amanah Rakyat (MARA) Malaysia.

\section{References}

1. D Mittal (1997) Silica from ash. Resonance 2(7): 64-66.

2. CY Yin, SASA Kadir, YP Lim, SNS Ariffin, Z Zamzuri (2008) An investigation into physicochemical characteristics of ash produced from combustion of oil palm biomass wastein a boiler. Fuel Processing Technology 89(7): 693-696.

3. HE Bergna, WO Roberts (2006) Colloidal Silica: Fundamentals and Applications. ( $1^{\text {st }}$ edn) CRC Press, Boca Raton: Taylor \& Francis pp. 9-37.

4. PK Jal, M Sudarshan, A Saha, Sabita Patel, BK Mishra (2004) Synthesis and characterization of nanosilica prepared by precipitation method. Colloids and Surfaces A: Physicochemical and Engineering Aspects 240(1-3): 173-178.

5. NA Rahman, I Widhiana, SR Juliastuti, H Setyawan (2015) Synthesis of mesoporous silica with controlled pore structure from bagasse ash as a silica source. Colloids and Surfaces A: Physicochemical and Engineering Aspects 476: 1-7.

6. S Norsuraya, H Fazlena, R Norhasyimi (2016) Sugarcane Bagasse as a Renewable Source of Silica to Synthesize Santa Barbara Amorphous-15 (SBA-15). Procedia Engineering 148: 839-846.

7. F Peng, JL Ren, F Xu, J Bian, P Peng, RC Sun (2009) Comparative study of hemicelluloses obtained by graded ethanol precipitation from sugarcane bagasse. Journal of Agricultural and Food Chemistry 57(14): 6305-6317.
To Submit Your Article Click Here: This work is licensed under Creative Commons Attribution 4.0 License

DOI: $10.32474 /$ AOICS.2018.03.000160

\section{Submit Article}

Citation: N Sapawe, MF Hanafi. Production of Silica from Agricultural Waste. Arc Org Inorg Chem Sci 3(2)- 2018. A0ICS.MS.ID.000160. DOI: 10.32474/AOICS.2018.03.000160.

\section{AOICS}

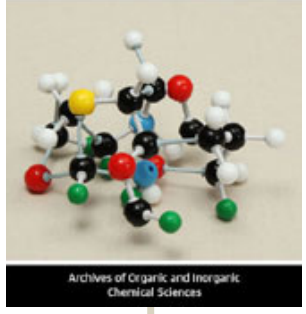

Archives of Organic and Inorganic Chemical Sciences

\section{Assets of Publishing with us}

- Global archiving of articles

- Immediate, unrestricted online access

- Rigorous Peer Review Process

- Authors Retain Copyrights

- Unique DOI for all articles 